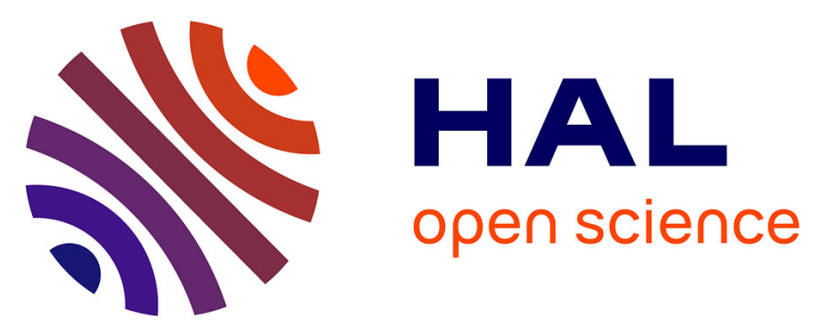

\title{
Design of cyclometallated 5- $\pi$-delocalized donor-1,3-di(2-pyridyl)benzene platinum(II) complexes with second-order nonlinear optical properties
}

N. Baggi, E. Garoni, A. Colombo, C. Dragonetti, S. Righetto, D. Roberto, J. Boixel, V. Guerchais, S. Fantacci

\section{To cite this version:}

N. Baggi, E. Garoni, A. Colombo, C. Dragonetti, S. Righetto, et al.. Design of cyclometallated 5- $\pi$ delocalized donor-1,3-di(2-pyridyl)benzene platinum(II) complexes with second-order nonlinear optical properties. Polyhedron, 2018, 140, pp.74-77. 10.1016/j.poly.2017.11.051 . hal-01695560

HAL Id: hal-01695560

https://hal-univ-rennes1.archives-ouvertes.fr/hal-01695560

Submitted on 12 Mar 2018

HAL is a multi-disciplinary open access archive for the deposit and dissemination of scientific research documents, whether they are published or not. The documents may come from teaching and research institutions in France or abroad, or from public or private research centers.
L'archive ouverte pluridisciplinaire HAL, est destinée au dépôt et à la diffusion de documents scientifiques de niveau recherche, publiés ou non, émanant des établissements d'enseignement et de recherche français ou étrangers, des laboratoires publics ou privés. 


\title{
Design of cyclometallated 5- $\pi$-delocalized donor-1,3-di(2-pyridyl)benzene platinum(II) complexes with second-order nonlinear optical properties.
}

Nicolò Baggi, ${ }^{a}$ Eleonora Garoni, ${ }^{a}$ Alessia Colombo, ${ }^{\text {a,b,c }}$ Claudia Dragonetti, ${ }^{\text {a,b,c }}$ Stefania Righetto, ${ }^{\text {a,b,c }}$ Dominique Roberto, ${ }^{\mathrm{a}, \mathrm{b}, \mathrm{c}}$ Julien Boixel, ${ }^{\mathrm{d}}$ Véronique Guerchais, ${ }^{* \mathrm{~d}}$ and Simona Fantacci*e

âDip. di Chimica dell'Università degli Studi di Milano, ${ }^{\mathrm{b}} \mathrm{UdR}$ di Milano dell'INSTM, 'Istituto di Scienze e Tecnologie Molecolari del CNR, via Golgi, 19, I-20133 Milano, Italy; ${ }^{\mathrm{d}}$ Institut des Sciences Chimiques de Rennes UMR 6226 CNRS-Université de Rennes 1, Campus de Beaulieu, 35042 Rennes Cedex, France; ${ }^{\mathrm{e}}$ Computational Laboratory for Hybrid/Organic Photovoltaics (CLHYO), CNR-ISTM, Via Elce di Sotto 8, I-06213, Perugia, Italy

Corresponding authors: alessia.colombo@unimi.it, veronique.guerchais@univ-rennes1.fr, simona@thch.unipg.it

\begin{abstract}
The effect on the second-order nonlinear optical properties of the nature of the $\pi$-delocalized moiety in the position 5 of a 1,3-di(2-pyridyl)benzene cyclometallated to a platinum(II) center was investigated. The influence of the substitution of a double bond with a triple bond as bridge between a triphenylamino group and the cyclometallated phenyl ring was studied and turned out to be negligible. Remarkably, the novel easily-prepared platinum(II) complex with a cyclometallated 5-styryl-1,3-di(2-pyridyl)benzene is characterized by a good second-order NLO response, as determined in solution by the EFISH technique; it is a good candidate for application in photonics.
\end{abstract}

Keywords: Second-order nonlinear optics; EFISH; cyclometallated platinum(II) complexes. 


\section{Introduction}

Compounds with second-order nonlinear optical (NLO) properties are of increasing interest as building blocks for the preparation of materials with potential applications in optical communications, optical data processing and storage, or electro-optical devices [1-2]. Their NLO response is closely related to intramolecular charge transfer and a donor-acceptor push-pull system is the traditional structure of second-order NLOphores [1-3]. Among them, coordination compounds are fascinating because they give additional flexibility, when compared to organic compounds, due to the presence of NLO-active charge-transfer transitions between the metal and the ligands, at relatively low energy and of high intensity, and tunable by the nature, oxidation state and coordination sphere of the metal center which may act as electron-donor or electron-acceptor [4-12].

In particular, the second-order NLO activity of substituted phenylpyridines increases upon cyclometallation, an effect that has led to cyclometallated $\mathrm{Ru}$ (II) [13], Ir(III) [14-24] and Pt(II) [24-25] complexes characterized by interesting NLO properties. Platinum(II) compounds incorporating an $N^{\wedge} N^{\wedge} C$-cyclometallated 6phenyl-2,2'-bipyridine constitutes another interesting NLO-active family [26-27]. Besides, it was reported that $\mathrm{Pt}(\mathrm{II})$ complexes with tridentate ligands based on a cyclometallated 1,3-di(2-pyridyl)benzene, which offer the metal ion an $\mathrm{N}^{\wedge} \mathrm{C}^{\wedge} \mathrm{N}$ coordination environment, are characterized by an enhanced NLO efficiency with respect to the corresponding $\mathrm{N}^{\wedge} \mathrm{N}^{\wedge} \mathrm{N}$-coordinated terpyridine complexes, as measured by the Hyper-Rayleigh Scattering technique [28]. The good second-order nonlinear optical properties of various platinum(II) complexes with a cyclometallated 1,3-di(2pyridyl)benzene have also been evidenced by the electric-field induced second harmonic generation (EFISH) technique [29]. In particular, the cyclometallated Pt(II) chloro complex of trans-5-( $p$-( $N, N$-diphenylamino)styryl)-1,3-di(2-pyridyl)benzene (Figure 1, Pt-1) is characterized by a good second-order NLO response mainly determined by a charge transfer transition from platinum- to the cyclometallated ligand [30].

These results prompted us to investigate by the EFISH technique the known Pt(II) complex bearing a cyclometallated 5-( $p$-( $N, N$-diphenylamino)phenylethynyl)-1,3-di(2pyridyl)benzene (Pt-2), previously studied for its luminescence properties and application in OLEDs [31], in order to understand the effect on the NLO properties of the substitution of a double bond by a triple bond as bridge between triphenylamino 
moiety and the cyclometallated phenyl ring. Besides, to verify the NLO importance of the $p$ - $(N, N$-diphenylamino) donor group on the styryl moiety, we prepared the simple novel platinum(II) complex bearing a trans-5-(styryl)-1,3-di(2-pyridyl)benzene (Pt-3).

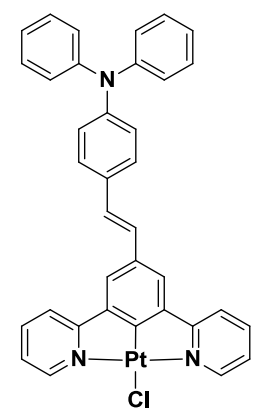

Pt-1

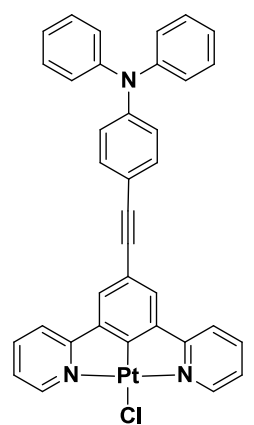

Pt-2

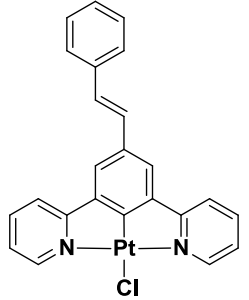

Pt-3

Figure 1. Investigated cyclometallated Pt(II) complexes.

\section{Material and methods}

\section{Synthesis}

\section{General comments}

All solvents were dried by standard procedures: THF was freshly distilled from $\mathrm{Na} /$ benzophenone under nitrogen atmosphere; $N, N$-dimethylformamide (DMF) was dried over activated molecular sieves, triethylamine $\left(\mathrm{Et}_{3} \mathrm{~N}\right)$ was freshly distilled over $\mathrm{KOH}$. All reagents were purchased from Sigma-Aldrich and were used without further purification. Reactions requiring anhydrous or oxygen-free conditions were performed under nitrogen. Thin layer chromatography (TLC) was carried out with pre-coated Merck $\mathrm{F}_{254}$ silica gel plates. Flash chromatography (FC) was carried out with Macherey-Nagel silica gel 60 (230400 mesh).

${ }^{1} \mathrm{H}$ and ${ }^{13} \mathrm{C}$ spectra were recorded at $400 \mathrm{MHz}$ on a Bruker AVANCE-400 instrument. Chemical shifts $(\delta)$ are expressed in ppm relative to internal $\mathrm{Me}_{4} \mathrm{Si}$ as standard. Signals are abbreviated as s, singlet; bs, broad singlet; d, doublet; t, triplet; q, quartet; m, multiplet. Mass spectra were obtained with a FT-ICR Mass Spectrometer APEX II \& Xmass software (Bruker Daltonics) - 4.7 Magnet and Autospec Fission Spectrometer (FAB ionization). Elemental analyses were performed using an Exeter Analytical E-440 analyser. UV-visible spectra were recorded for solutions of the compounds in dichloromethane, in $1 \mathrm{~cm}$ pathlength quartz cuvettes using a Biotek Instruments XS spectrometer. 


\section{EFISH measurements}

EFISH measurements [32] were carried out at the Dipartimento di Chimica of the Università di Milano, in DMF solutions at a concentration of $10^{-3} \mathrm{M}$, with a nonresonant incident wavelength of $1.907 \mu \mathrm{m}$, obtained by Raman-shifting the fundamental $1.064 \mu \mathrm{m}$ wavelength produced by a Q-switched, mode-locked $\mathrm{Nd}^{3+}$ :YAG laser manufactured by Atalaser. The apparatus used for EFISH measurements is a prototype made by SOPRA (France). The $\mu \beta_{\mathrm{EFISH}}$ values reported are the mean values of 16 measurements performed on the same sample. The sign of $\mu \beta_{\text {EFISH }}$ is determined by comparison with the solvent.

\section{Dipole moments calculation}

All the reported calculations were performed with Gaussian09 (G09) [33] without any symmetry constraints. The molecular geometry of Pt-1, Pt-2 and Pt-3 has been optimized in DMF solution by a Density Functional theory (DFT) approach using the B3LYP [34] exchange-correlation functional. For $\mathrm{Pt}$ a LANL2DZ basis set [35] along with the corresponding pseudopotentials have been used, while all the other atoms have been described with a 6-31G* basis set [36]. DMF solvation effects were included in the calculations by means of the conductor-like polarizable continuum model (C-PCM) as implemented in G09 [37]. Ground state dipole moments of the Pt compounds have been computed in DMF solution and have been used in the evaluation of $\beta_{\text {EFISH }}$ from $\mu \beta_{\text {EFISH. }}$

\section{Synthesis of the platinum (II) complexes}

Diethyl 3,5-dibromobenzylphosphonate was prepared according to the literature [38] Stille couplings were performed following a reported procedure [39], using 2-(tri- $n$ butylstannyl)pyridine freshly prepared according to the literature [40]. Complexes Pt-1 and Pt-2, previously studied for their luminescence properties, were prepared as reported by some of us [30-31]. The novel complex Pt-3 was prepared as shown in Scheme 1 by reaction of $\mathrm{K}_{2} \mathrm{PtCl}_{4}$ with the new pro-ligand $\mathbf{L - 3}$ obtained as follows. 


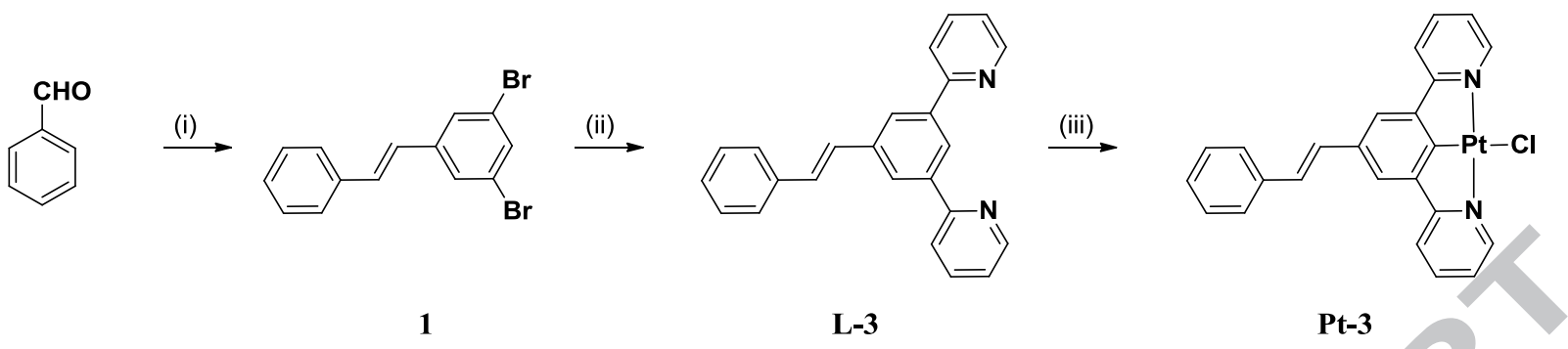

Scheme 1. Reagents and conditions: (i) Diethyl 3,5-dibromobenzylphosphonate, $t$-BuOK, THF, Ar, $0^{\circ} \mathrm{C}$, then rt, $15 \mathrm{~h}, 58 \%$ yield; (ii) 2-(tri- $n$-butylstannyl)pyridine, $\mathrm{LiCl}, \mathrm{PdCl}_{2}\left(\mathrm{PPh}_{3}\right)_{2}$, toluene, $110^{\circ} \mathrm{C}, 48 \mathrm{~h}, 48 \%$ yield; (iii) $\mathrm{K}_{2} \mathrm{PtCl}_{4}, \mathrm{AcOH}, 118^{\circ} \mathrm{C}, 48 \mathrm{~h}, 77 \%$ yield.

1: Diethyl 3,5-dibromobenzylphosphonate $(698 \mathrm{mg}, 1.8 \mathrm{mmol})$ and benzaldehyde (230 $\mathrm{mg}$, $2.1 \mathrm{mmol})$ were dissolved in THF (20mL) under Ar atmosphere at $0^{\circ} \mathrm{C} . t$-BuOK $(808 \mathrm{mg}, 72$ mmol) was added in small portions to the solution over 20 minutes, keeping the mixture under stirring. The mixture was then allowed to warm gradually at room temperature and stirred overnight. Afterwards, $\mathrm{H}_{2} \mathrm{O}$ was added causing the formation of a precipitate and the mixture was stirred for 30 minutes. The solvent was partially removed under reduced pressure, the residue was extracted into $\mathrm{CH}_{2} \mathrm{Cl}_{2}$, the organic layer was dried over $\mathrm{MgSO}_{4}$ and the solvent removed under reduced pressure. The crude product was purified by flash chromatography (silica, hexane: $\mathrm{CH}_{2} \mathrm{Cl}_{2}, 7: 3$ ). The pure compound was obtained as a yellow solid (412 mg). Yield: $58 \% .{ }^{1} \mathrm{H}-\mathrm{NMR}\left(400 \mathrm{MHz}, \mathrm{CDCl}_{3}\right) \delta(\mathrm{ppm}): 7.56(2 \mathrm{H}, \mathrm{d}, J=1.6 \mathrm{~Hz}), 7.53(1 \mathrm{H}, \mathrm{t}, J=$ $1.7 \mathrm{~Hz}), 6.49(2 \mathrm{H}, \mathrm{d}, J=8.0 \mathrm{~Hz}), 7.38(2 \mathrm{H}, \mathrm{t}, J=7.8 \mathrm{~Hz}), 7.30(1 \mathrm{H}, \mathrm{m}), 7.09(1 \mathrm{H}, \mathrm{d}, J=16.2$ $\mathrm{Hz}), 6.92(1 \mathrm{H}, \mathrm{d}, J=16.2 \mathrm{~Hz}) .{ }^{13} \mathrm{C}-\mathrm{NMR}\left(101 \mathrm{MHz}, \mathrm{CDCl}_{3}\right) \delta(\mathrm{ppm}): 141.0,136.3,132.6$, $131.5,128.8,128.4,128.8,126.8,125.6,123.2$.

L-3. A mixture of the bromo derivative (410 mg, $1.06 \mathrm{mmol})$, 2-(tri- $n$-butylstannyl)pyridine (858 mg, $2.33 \mathrm{mmol}), \mathrm{PdCl}_{2}\left(\mathrm{PPh}_{3}\right)_{2}(37 \mathrm{mg}, 0.05 \mathrm{mmol})$ and $\mathrm{LiCl}(360 \mathrm{mg}, 8.48 \mathrm{mmol})$ were suspended in toluene $(10 \mathrm{~mL})$ and heated at reflux under argon atmosphere for $48 \mathrm{~h}$. After cooling to room temperature, an aqueous solution of $\mathrm{NaOH} 1 \mathrm{M}$ was added. The resulting solution was extracted with AcOEt and the organic layer was dried over $\mathrm{MgSO}_{4}$ and the solvent removed under reduced pressure. The crude product was purified by flash chromatography (silica, petroleum ether/ $\mathrm{Et}_{2} \mathrm{O}, 1: 1$ ). The desired product was obtained as a white solid (160 mg). Yield: 45\%. ${ }^{1} \mathrm{H}$ NMR (400 MHz, $\left.\mathrm{CD}_{2} \mathrm{Cl}_{2}\right) \delta(\mathrm{ppm}): 8.76(2 \mathrm{H}, \mathrm{d}, J=4.2$ $\mathrm{Hz}), 8.51(1 \mathrm{H}, \mathrm{s}), 8.26(2 \mathrm{H}, \mathrm{s}), 7.89(2 \mathrm{H}, \mathrm{d}, J=7.8 \mathrm{~Hz}), 7.80(2 \mathrm{H}, \mathrm{t}, J=7.6 \mathrm{~Hz}), 7.58(2 \mathrm{H}, \mathrm{d}$, $J=7.4 \mathrm{~Hz}), 7.40$, (2H, t, $J=7.5 \mathrm{~Hz}), 7.29(5 \mathrm{H}, \mathrm{m}) .{ }^{13} \mathrm{C}-\mathrm{NMR}\left(101 \mathrm{MHz}, \mathrm{CD}_{2} \mathrm{Cl}_{2}\right) \delta(\mathrm{ppm})$ : $157.1,149.7,140.3,138.5,137.3,136.8,129.6,128.8,128.4,127.8,126.6,125.7,124.7$, 
122.4, 120.8. Elem. Anal. calcd for $\mathrm{C}_{24} \mathrm{H}_{18} \mathrm{~N}_{2}$ : C, 86.20; H, 5.43; N, 8.38. Found: C, 86.60; H, $5.45 ; \mathrm{N}, 8.42$.

Pt-3. The pro-ligand L-3 (100 mg, $0.3 \mathrm{mmol})$ was dissolved in acetic acid $(5 \mathrm{ml})$. The solution was degassed through freeze-pump-thaw cycles. $\mathrm{K}_{2} \mathrm{PtCl}_{4}(149 \mathrm{mg}, 0.36 \mathrm{mmol})$ was added and the mixture was heated at reflux for 2 days. A yellow precipitate formed: it was filtered, washed with $\mathrm{MeOH}, \mathrm{H}_{2} \mathrm{O}, \mathrm{EtOH}$ and $\mathrm{Et}_{2} \mathrm{O}$ and dried under vacuum to obtain pure Pt3 as a yellow powder (130 mg). Yield: $77 \% .{ }^{1} \mathrm{H}$ NMR (400 MHz, $\left.\mathrm{CD}_{2} \mathrm{Cl}_{2}\right) \delta(\mathrm{ppm}): 9.33(2 \mathrm{H}$, $\mathrm{dt}, J=16.1 \mathrm{~Hz}, 6.6 \mathrm{~Hz}), 8.05(2 \mathrm{H}, \mathrm{t}, J=7.7 \mathrm{~Hz}), 7.71(2 \mathrm{H}, \mathrm{s}), 7.62(2 \mathrm{H}, \mathrm{d}, J=7.9 \mathrm{~Hz}), 7.36$ $(8 \mathrm{H}, \mathrm{m}), 7.21(1 \mathrm{H}, \mathrm{d}, J=16.2 \mathrm{~Hz})$. Elem. Anal. calcd for $\mathrm{C}_{24} \mathrm{H}_{17} \mathrm{ClN}_{2} \mathrm{Pt}$ : C, 51.12; H, 3.04; N, 4.97. Found: C, 51.34; H, 3.05; N, 4.95. MS (FAB $\left.{ }^{+}\right)$, calculated: $\left(\mathrm{C}_{24} \mathrm{H}_{17} \mathrm{~N}_{2} \mathrm{Pt}\right): \mathrm{m} / \mathrm{z} 528.10$ [M-Cl]. Found: m/z 528 [M-Cl].

\section{Results and Discussion}

The investigated platinum(II) complexes (Figure 1) are readily prepared by reaction of $\mathrm{K}_{2} \mathrm{PtCl}_{4}$ with the related 5- $\pi$-delocalized donor-1,3-di(2-pyridyl)benzene pro-ligand dissolved in acetic acid (see Material and methods).

The main absorption bands in the UV-visible spectra, carried out in $\mathrm{CH}_{2} \mathrm{Cl}_{2}$ at $298 \mathrm{~K}$, are given in Table 1. Like other platinum(II) complexes with a cyclometallated 1,3-di(2pyridyl)benzene, Pt-3 shows a strong band at $263 \mathrm{~nm}$, which can be assigned to intraligand ${ }^{1} \pi-\pi^{*}$ transitions of the cyclometallated 1,3-di(2-pyridyl)benzene, and a less-intense absorption band at $421 \mathrm{~nm}$ in agreement with transitions of mixed charge-transfer/ligandcentered character [29].

Table 1. Main absorption bands in the UV-visible spectra, dipole moments and second-order NLO response.

\begin{tabular}{|c|c|c|c|c|}
\hline & $\begin{array}{c}\text { Absorption }^{\mathbf{a}} \\
\lambda_{\max } / \mathrm{nm} \\
\left(\varepsilon / \mathrm{M}^{-1} \mathrm{~cm}^{-1}\right)\end{array}$ & $\begin{array}{c}\mu \boldsymbol{\beta}_{\text {EFISH }} \mathbf{b} \\
\left(\times 10^{-48} \mathrm{esu}\right)\end{array}$ & $\begin{array}{c}\boldsymbol{\mu}^{\mathbf{c}} \\
(\mathrm{D})\end{array}$ & $\begin{array}{c}\boldsymbol{\beta}_{\text {EFISH }} \\
\left(\times 10^{-30} \mathrm{esu}\right)\end{array}$ \\
\hline Pt-1 $^{\mathbf{d}}$ & $295(21000), 378(15700), 430 \mathrm{sh}(4900)$ & -880 & 10.7 & -82 \\
\hline Pt-2 & $\begin{array}{c}240(35100), 292(27100), 338 \mathrm{sh} \\
(18200), 363(22800), 416 \mathrm{sh}(6380)\end{array}$ & -764 & 11.0 & -69 \\
\hline Pt-3 & $263(9441), 421(2364)$ & -660 & 9.5 & -69 \\
\hline
\end{tabular}

(a) $\mathrm{In}_{\mathrm{CH}_{2}} \mathrm{Cl}_{2}$. (b) in DMF at $1.907 \mu \mathrm{m}$; estimated uncertainty in EFISH measurements is $\pm 10 \%$. (c) computed dipole moments in DMF solution using B3LYP//6-31g*/LANL2DZ// C-PCM level of theory. (d) from reference 30. 
The quadratic hyperpolarizability of the three complexes was measured by the solution phase direct current EFISH generation method, which can provide direct information on the intrinsic molecular NLO properties through eq 1:

$$
\gamma_{\mathrm{EFISH}}=\left(\mu \beta_{\lambda} / 5 k T\right)+\gamma(-2 \omega ; \omega, \omega, 0)
$$

where $\mu \beta_{\lambda} / 5 k T$ is the dipolar orientational contribution and $\gamma(-2 \omega ; \omega, \omega, 0)$ is the third-order polarizability corresponding to the mixing of two optical fields at $\omega$ and the dc poling field at $\omega=0$. This latter term is often referred as the electronic cubic contribution to $\gamma_{\text {EFISH }}$, which is usually negligible. $\beta_{\lambda}$ is the projection along the dipole moment $(\mu)$ axis of the vectorial component of the tensor of the quadratic hyperpolarizability at the incident wavelength $\lambda$. All EFISH measurements were carried out working in $\mathrm{CH}_{2} \mathrm{Cl}_{2}$ solutions at a concentration of $10^{-3}$ $\mathrm{M}$, with a non resonant incident wavelength of $1.907 \mu \mathrm{m}$, obtained by Raman-shifting in a high pressure $\mathrm{H}_{2}$ of the fundamental $1.064 \mu \mathrm{m}$ wavelength produced by a Q-switched, modelocked $\mathrm{Nd}^{3+}:$ YAG laser.

All complexes are characterized by a negative value of $\mu \beta_{\text {EFISH }}$ (Table 1 ), as determined by the EFISH technique working in DMF solution. This negative sign is in agreement with a decrease of the excited state dipole moment with respect to the ground state [41], suggesting that the second-order dipolar NLO response is dominated by the charge transfer from platinum to the cyclometallated ligand [29-30]. In order to obtain the $\beta_{\mathrm{EFISH}}$ values, we calculated the dipole moments in DMF solution. The optimized structures were oriented in all cases with the 1,3-di(2-pyridyl)benzene moiety in the xy plane and with the y axis crossing the Pt center. The optimized geometries of complexes Pt-1, Pt-2 and Pt-3 are reported in Figure 1 along with the corresponding y component of the dipole moments $\left(\mu_{\mathrm{y}}\right)$, whereas the total dipole moments $(\mu)$ are reported in Table 1 . It appears that $\mu_{\mathrm{y}}$ and $\mu$ are basically coincident, reflecting that the dipole moment is located mainly along the $y$ axis, which is in agreement with a $\mathrm{C}_{2 \mathrm{v}}$ symmetry of the molecular architecture. 


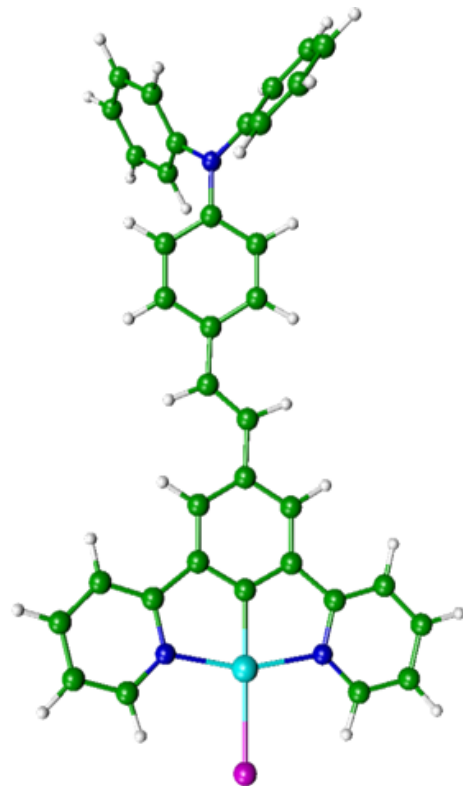

Pt-1

$\mu_{\mathrm{y}}=10.7$

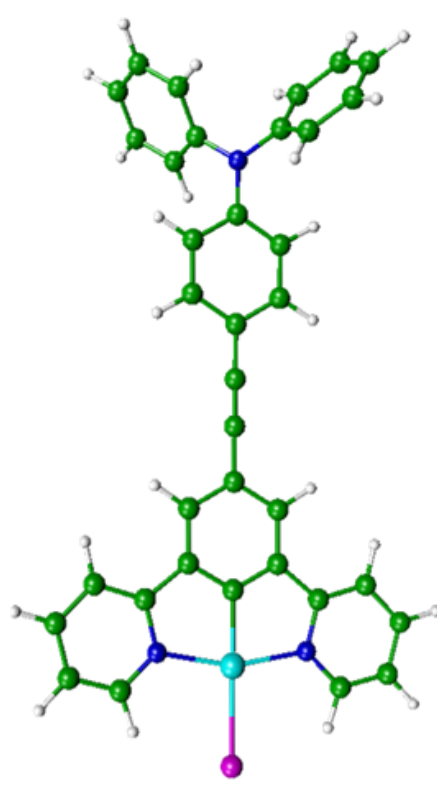

Pt-2

$\mu_{\mathrm{y}}=10.9$
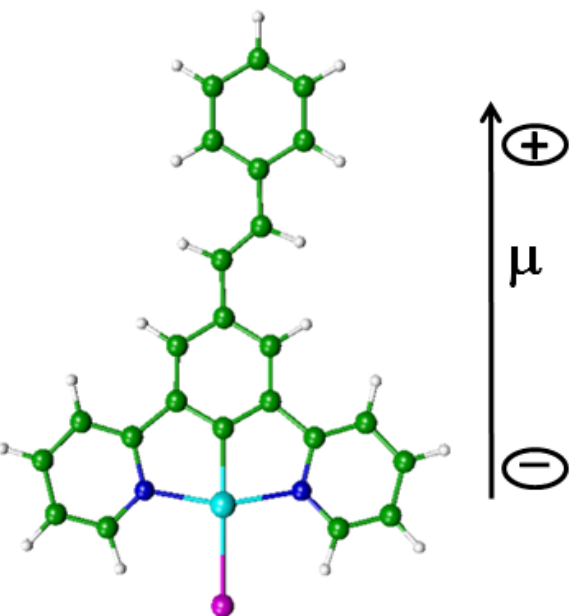

Pt-3

$\mu_{\mathrm{y}}=9.5$

Figure 2. The optimized geometry of complexes Pt-1, Pt-2 and Pt-3 and the dipole moment, calculated in DMF and expressed in Debye, along the y axis.

Complexes Pt-1 and Pt-2 are characterized by a similar dipole moment, a bit higher than that of Pt-3 which lacks the triphenylamino moiety. The $\beta_{\text {EFISH }}$ value of Pt-1 is quite similar to that of Pt-2, showing that the substitution of a double bond by a triple bond, as bridge between the triphenyl amino moiety and the cyclometallated ring (Figure 2), has a negligible NLO influence in this kind of complexes. This is an interesting result because in push-pull organic compounds an acetylenic bridge leads to a much lower NLO response than an ethylenic bridge [42]. Besides, remarkably, it turned out that the easily-prepared novel

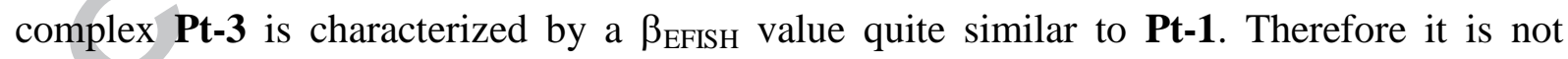
necessary to have a donor substituent on the styryl group in order to reach a high second-order NLO response, an important observation from a synthetic point of view. Besides, it is worth pointing out that all the complexes investigated here are characterized by better $\mu \beta_{\mathrm{EFISH}}$

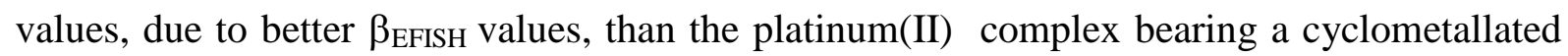
5-methyl-1,3-di(2-pyridyl)benzene $\left(\mu \beta_{\text {EFISH }}=-480 \times 10^{-48}\right.$ esu; $\beta_{\text {EFISH }}=-47 \times 10^{-30}$ esu $)$ [29], showing the crucial role of the $\pi$-delocalized polarizable moiety on the NLO properties. 


\section{Conclusion}

In conclusion, our work gives some indications for the design of easily prepared 5- $\pi$ delocalized donor-1,3-di(2-pyridyl)benzene platinum(II) complexes with interesting secondorder nonlinear optical properties. Remarkably, the simple platinum complex bearing a cyclometallated 5-styryl-1,3-di(2-pyridyl)benzene shows a good quadratic hyperpolarizability and has a great potential for application in photonics.

\section{Acknowledgements}

This work was supported by MIUR and CNR in Italy. We thank CNRS for a financial support (PICS Rennes-Milan) and 1'Università Italo Francese (Progetto Galileo 2015/2016; G15_50) for mobility support.

\section{References}

[1] N. P. Prasad, D. J. Williams, In Introduction to Nonlinear Optical Effects in molecules and Polymers; Wiley, 1991.

[2] J. Zyss, Molecular Nonlinear Optics: Materials, Physics and Devices, Academic Press, Boston, 1994.

[3] (a) L. Beverina, R. Ruffo, G. Patriarca, F. De Angelis, D. Roberto, S. Righetto, R. Ugo, G.A. Pagani, J. Mater. Chem. 19 (2009) 8190-8197. (b) E. Cariati, C. Dragonetti, E. Lucenti, F. Nisic, S. Righetto, D. Roberto, E. Tordin, Chem. Commun. 50 (2014) 1608-1610.

[4] B. J. Coe, Acc. Chem. Res. 39 (2006) 383-393.

[5] E. Cariati, M. Pizzotti, D. Roberto, F. Tessore, R. Ugo, Coord. Chem. Rev. 250 (2006)

\section{0-1233}

[6] J. P. Morrall, G. T. Dalton, M.G.Humphrey, M. Samoc, Adv. Organomet. Chem. 55 (2007) 61-136.

[7] S. Di Bella, C. Dragonetti, M. Pizzotti, D. Roberto, F. Tessore, R. Ugo in Topics in Organometallic Chemistry 28. Molecular Organometallic Materials for Optics, Vol. 28 (Eds: H. Le Bozec, V. Guerchais), Springer, 2010, 1-55.

[8] O. Maury, H. Le Bozec, in Molecular Materials; D.W. Bruce, D. O’Hare and R.I. Walton, Eds.; Wiley: Chichester, 2010, 1-59.

[9] O. Maury, H. Le Bozec, Acc. Chem. Res. 38 (2005) 691-704. 
[10] F. Tessore, D. Roberto, R. Ugo, P. Mussini, S. Quici, I. Ledoux-Rak, J. Zyss, Angew. Chem. Intern. Ed. 42 (2003) 456.

[11] I.P. Oliveri, S. Failla, A. Colombo, C. Dragonetti, S. Righetto, S. Di Bella, Dalton Trans., 43 (2014) 2168.

[12] M.G. Humphrey, T. Schwich, P.J. West, M.P. Cifuentes, M. Samoc, In Comprehensive Inorganic Chemistry II (Second Edition): From Elements to Applications, Elsevier: Oxford, U.K. 2013; Vol 8.

[13] L. Labat, J.F. Lamere, I. Sasaki, P.G. Lacroix, L. Vendier, I. Asselberghs, J. PerezMoreno, K. Clays, Eur. J. Inorg. Chem. 15 (2006) 3105.

[14] C. Dragonetti, S. Righetto, D. Roberto, R. Ugo, A. Valore, S. Fantacci, A. Sgamellotti, F. De Angelis, Chem. Commun. 40 (2007) 4116.

[15] C. Dragonetti, S. Righetto, D. Roberto, R. Ugo, A. Valore, F. Demartin, F. De Angelis, A. Sgamellotti, S. Fantacci, Inorg. Chim. Acta 361 (2008) 4070.

[16] C. Dragonetti, S. Righetto, D. Roberto, A. Valore, T. Benincori, F. Sannicolò, F. De Angelis, S. Fantacci, J. Mat. Sci.: Mat. Electr. 20 (2009) S460.

[17] C. Dragonetti, S. Righetto, D. Roberto, A. Valore, Phys. Status Solid C 6 (2009) S50.

[18] A. Valore, E. Cariati, C. Dragonetti, S. Righetto, D. Roberto, R. Ugo, F. De Angelis, S. Fantacci, A. Sgamellotti, A. Macchioni, D. Zuccaccia, Chem. Eur. J. 16 (2010) 4814.

[19] V. Aubert, L. Ordronneau, M. Escadeillas, J.A.G. Williams, A. Boucekkine, E. Coulaud, C. Dragonetti, S. Righetto, D. Roberto, R. Ugo, A. Valore, A. Singh, J. Zyss, I. Ledoux-Rak, H. Le Bozec, V. Guerchais, Inorg. Chem. 50 (2011) 5027.

[20] C. Dragonetti, A. Valore, A. Colombo, S. Righetto, G. Rampinini, F. Colombo, L. Rocchigiani, A. Macchioni, Inorg. Chim. Acta 382 (2012) 72.

[21] M. Zaarour, V. Guerchais, H. Le Bozec, C. Dragonetti, S. Righetto, D. Roberto, F. De Angelis, S. Fantacci, M.G. Lobello, Dalton Trans. 42 (2013) 155.

[22] M. Zaarour, A. Singh, C. Latouche, J.A.G. Williams, I. Ledoux-Rak, J. Zyss, A. Boucekkine, H. Le Bozec, V. Guerchais, C. Dragonetti, A. Colombo, D. Roberto, A. Valore, Inorg. Chem. 52 (2013) 7987.

[23] C. Dragonetti, A. Colombo, D. Marinotto, S. Righetto, D. Roberto, A. Valore, M. Escadeillas, V. Guerchais, H. Le Bozec, A. Boucekkine, C. Latouche, J. Organomet. Chem. 751 (2014) 568.

[24] A. Valore, A. Colombo, C. Dragonetti, S. Righetto, D. Roberto, R. Ugo, F. De Angelis, S. Fantacci, Chem. Commun. 46 (2010) 2414. 
[25] A. Colombo, C. Dragonetti, D. Marinotto, S. Righetto, D. Roberto, S. Tavazzi, M. Escadeillas, V. Guerchais, H. Le Bozec, A. Boucekkine, C. Latouche, Organometallics 32 (2013) 3890 .

[26] J. Boixel, V. Guerchais, H. Le Bozec, D. Jacquemin, A. Amar, A. Boucekkine, A. Colombo, C. Dragonetti, D. Marinotto, D. Roberto, S. Righetto, R. De Angelis, J. Am. Chem. Soc. 136 (2014) 5367.

[27] J. Boixel, V. Guerchais, H. Le Bozec, A. Chantzis, D. Jacquemin, A. Colombo, C. Dragonetti, D. Marinotto, D. Roberto, Chem. Commun. 51 (2015) 7805.

[28] A. Scarpaci, C. Monnereau, N. Hergué, E. Blart, S. Legoupy, F. Odobel, A. Gorfo, J. Pérez-Moreno, K. Clays, I. Asselberghs, Dalton Trans. (2009) 4538.

[29] E. Rossi, A. Colombo, C. Dragonetti, S. Righetto, D. Roberto, R. Ugo, A. Valore, J. A. G. Williams, M. G. Lobello, F. De Angelis, S. Fantacci, I. Ledoux-Rak, A. Singh, J. Zyss, Chem. Eur. J. 19 (2013) 9875.

[30] F. Nisic, E. Cariati, A. Colombo, C. Dragonetti, S. Fantacci, E. Garoni, E. Lucenti, S.

Righetto, D. Roberto, J. A. G. Williams, Dalton Trans. 46 (2017) 1179-1185.

[31] F. Nisic, A. Colombo, C. Dragonetti, D. Roberto, A. Valore, J. M. Malicka, M. Cocchi, G. R. Freeman, J.A.G. Williams, J. Mater. Chem. C 2 (2014) 1791-1800.

[32] (a) B. F. Levine, C. G. Bethea, Appl. Phys. Lett. 24 (1974) 445. (b) B. F. Levine, C. G. Bethea, J. Chem. Phys. 63 (1975) 2666. (c) I. Ledoux, J. Zyss, Chem. Phys. 73 (1982) 203.

[33] M. J. Frisch, G. W. Trucks, H. B. Schlegel, G. E. Scuseria, M. A. Robb, J. R. Cheeseman, G. Scalmani, V. Barone, B. Mennucci, G. A. Petersson, H. Nakatsuji, M. Caricato, X. Li, H. P. Hratchian, A. F. Izmaylov, J. Bloino, G. Zheng, J. L. Sonnenberg, M. Hada, M. Ehara, K. Toyota, R. Fukuda, J. Hasegawa, M. Ishida, T. Nakajima, Y. Honda, O. Kitao, H. Nakai, T. Vreven, J. A. Montgomery Jr., J. E. Peralta, F. Ogliaro, M. Bearpark, J. J. Heyd, E. Brothers, K. N. Kudin, V. N. Staroverov, R. Kobayashi, J. Normand, K. Raghavachari, A. Rendell, J. C. Burant, S. S. Iyengar, J. Tomasi, M. Cossi, N. Rega, J. M. Millam, M. Klene, J. E. Knox, J. B. Cross, V. Bakken, C. Adamo, J. Jaramillo, R. Gomperts, R. E. Stratmann, O. Yazyev, A. J. Austin, R. Cammi, C. Pomelli, J. W. Ochterski, R. L. Martin, K. Morokuma, V. G. Zakrzewski, G. A. Voth, P. Salvador, J. J. Dannenberg, S. Dapprich, A. D. Daniels, Ö. Farkas, J. B. Foresman, J. V. Ortiz, J. Cioslowski, D. J. Fox, Gaussian 09, Revision D.01, Gaussian, Inc., Wallingford CT, 2009.

[34] (a) A. D. Becke, J. Chem. Phys. 98 (1993) 5648-5652. (b) C. Lee, W. Yang, R. G. Parr, Phys. Rev. B: Condens. Matter 37 (1988) 785-789. (c) B. Miehlich, A. Savin, H. Stoll, H. Preuss, Chem. Phys. Lett. 157 (1989) 200-206. 
[35] P. J. Hay, W. R. Wadt, J. Chem. Phys. 82 (1985) 299-310.

[36] G. A. Petersson, M. A. Al-Laham, J. Chem. Phys. 94 (1991) 6081-6101.

[37] (a) S. Miertus, E. Scrocco, J. Tomasi, Chem. Phys. 55 (1981) 117-129; (b) M. Cossi, V.

Barone, R. Cammi, J. Tomasi, Chem. Phys. Lett. 255 (1996) 327-335.

[38] E. Diez-Barra, J. C. Garcia-Martinez, S. Merino, R. Del Rey, J. Rodriguez-Lopez, P. Sanchez-Verdu, J. Tejeda, J. Org. Chem. 66 (2001) 5664-5670.

[39] X.-S. Xiao, W. Lu, C.-M. Che, Chem. Sci. 5 (2014) 2482-2488.

$[40$

Gueńeé, C. Besnard, C. Piguet, Inorg.

Chem. 52 (2013) 5570-5580.

[41] D. R. Kanis, P. G. Lacroix, M. A. Ratner, T. J. Marks, J. Am. Chem. Soc. 116 (1994) 10089-10102.

[42] L.T. Cheng, W. Tam, S.R. Marder, A.E. Stiegman, G. Rikken, C.W. Spangler, J. Phys. Chem. 95 (1991) 10643-10652. 


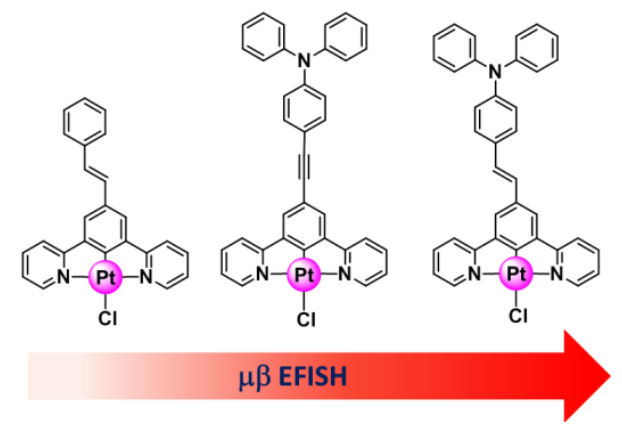

The novel easily-prepared platinum(II) complex with a cyclometallated 5-styryl-1,3-di(2pyridyl)benzene is characterized by a good second-order NLO response, as determined in solution by the EFISH technique and it is a good candidate for application in photonics. 